\title{
Prospective study of a community reintegration programme for patients with acquired chronic brain injury: Effects on caregivers" emotional burden and family functioning
}

Citation for published version (APA):

Geurtsen, G. J., van Heugten, C. M., Meijer, R., Martina, J. D., \& Geurts, A. C. H. (2011). Prospective study of a community reintegration programme for patients with acquired chronic brain injury: Effects on caregivers" emotional burden and family functioning. Brain Injury, 25(7-8), 691-697.

https://doi.org/10.3109/02699052.2011.574675

Document status and date:

Published: 01/01/2011

DOI:

10.3109/02699052.2011.574675

Document Version:

Publisher's PDF, also known as Version of record

Document license:

Taverne

Please check the document version of this publication:

- A submitted manuscript is the version of the article upon submission and before peer-review. There can be important differences between the submitted version and the official published version of record. People interested in the research are advised to contact the author for the final version of the publication, or visit the DOI to the publisher's website.

- The final author version and the galley proof are versions of the publication after peer review.

- The final published version features the final layout of the paper including the volume, issue and page numbers.

Link to publication

\footnotetext{
General rights rights.

- You may freely distribute the URL identifying the publication in the public portal. please follow below link for the End User Agreement:

www.umlib.nl/taverne-license

Take down policy

If you believe that this document breaches copyright please contact us at:

repository@maastrichtuniversity.nl

providing details and we will investigate your claim.
}

Copyright and moral rights for the publications made accessible in the public portal are retained by the authors and/or other copyright owners and it is a condition of accessing publications that users recognise and abide by the legal requirements associated with these

- Users may download and print one copy of any publication from the public portal for the purpose of private study or research.

- You may not further distribute the material or use it for any profit-making activity or commercial gain

If the publication is distributed under the terms of Article 25fa of the Dutch Copyright Act, indicated by the "Taverne" license above, 


\section{Brain Injury}

$\cos 20$

\section{Prospective study of a community reintegration programme for patients with acquired chronic brain injury: Effects on caregivers' emotional burden and family functioning}

Gert J. Geurtsen, Caroline M. van Heugten, Ron Meijer, Juan D. Martina \& Alexander C. H. Geurts

To cite this article: Gert J. Geurtsen, Caroline M. van Heugten, Ron Meijer, Juan D. Martina \& Alexander C. H. Geurts (2011) Prospective study of a community reintegration programme for patients with acquired chronic brain injury: Effects on caregivers' emotional burden and family functioning, Brain Injury, 25:7-8, 691-697, DOI: 10.3109/02699052.2011.574675

To link to this article: https://doi.org/10.3109/02699052.2011.574675

\section{曲 Published online: 11 May 2011.}

\section{Submit your article to this journal $\sqsubset$}

Llll Article views: 599

Q View related articles $\square$

Citing articles: 2 View citing articles $\square$ 


\title{
ORIGINAL ARTICLE
}

\section{Prospective study of a community reintegration programme for patients with acquired chronic brain injury: Effects on caregivers' emotional burden and family functioning}

\author{
GERT J. GEURTSEN ${ }^{1}$, CAROLINE M. VAN HEUGTEN ${ }^{2,3}$, RON MEIJER ${ }^{1,4,5}$, \\ JUAN D. MARTINA ${ }^{1}$, \& ALEXANDER C. H. GEURTS ${ }^{4,5}$ \\ ${ }^{1}$ Department for Acquired Brain Injury, Rehabilitation Medical Centre Groot Klimmendaal, Arnhem, \\ The Netherlands, ${ }^{2}$ Department of Psychiatry and Neuropsychology, School for Mental Health and Neuroscience, \\ ${ }^{3}$ Department of Neuropsychology and Psychopharmacology, Maastricht University, Maastricht, The Netherlands, \\ ${ }^{4}$ Department of Rehabilitation, Nijmegen Centre for Evidence Based Practice, Radboud University Nijmegen Medical \\ Centre, Nijmegen, The Netherlands, and ${ }^{5}$ Research Development and Education, St. Maartenskliniek, Nijmegen, \\ The Netherlands
}

(Received 17 September 2010; revised 31 fanuary 2011; accepted 21 March 2011)

\begin{abstract}
Objective: To examine the effects of a residential community reintegration programme for patients with psychosocial problems due to acquired chronic brain injury on caregivers' emotional burden and family functioning.

Design: A prospective cohort study with waiting list control and 1-year follow-up.

Subjects: Forty-one caregivers of which 28 female. Mean age was $48 \pm 8.3$ years and 33 caregivers were parents.

Intervention: A structured residential treatment programme was offered to the patients directed at domestic life, work, leisure time and social interactions.

Measures: The Involvement Evaluation Questionnaire for Brain Injury (IEQ-BI) for emotional burden, the General Health Questionnaire (GHQ) for psychological health and the Family Assessment Device (FAD) for family functioning were used. Results: There was an overall significant effect of Time for all outcome measures (MANOVA $T^{2}=9.1, F_{15,317}=64.1$, $p=0.000$ ). The effect sizes were moderate for three IEQ-BI sub-scales (partial $\eta^{2}=0.12-0.17$ ) and small for two sub-scales (partial $\eta^{2}=0.05-0.09$ ). The effect size for GHQ was moderate (partial $\eta^{2}=0.11$ ). As for FAD no significant time effects were present (partial $\left.\eta^{2}=0.00-0.04\right)$.

Conclusions: Emotional burden and psychological health of the caregivers improved significantly when patients with acquired brain injury and psychosocial problems followed a residential community reintegration programme. Family dynamics remained stable.
\end{abstract}

Keywords: Chronic brain injury, caregiver burden, rehabilitation outcome, residential treatment

\section{Introduction}

Brain injury has considerable consequences for the family and other caregivers of the patients. High levels of experienced burden can lead to deterioration in caregivers' health status, social life, well-being and psychological health $[1,2]$. Furthermore, a high degree of caregivers' burden can have negative effects on the well-being of the persons with brain injury and their rehabilitation outcome $[2,3]$.

Research has given some understanding of the effect of brain injury on the caregivers. It appears that caregivers are likely to benefit from specific 
treatment [4]. In their critical review, Visser-Meily et al. [2] found that counselling had the most positive effects when given individually for at least 8 hours and focused on the problems of the caregivers themselves. However, according to a more recent systematic review on family interventions for brain injury populations, research in this field is still in its infancy and there is not much evidence yet available to formulate recommendations for daily clinical practice [5].

It may be that not so much the physical care for the patient, but the continuous sense of responsibility for and concerns about the brain injured person leads to experienced emotional burden by the caregiver [6]. Specifically patients with psychosocial problems experience difficulties with community reintegration, which may lead to an emotional burden on their caregivers. Rehabilitation programmes addressing the patients' level of functioning and participation can, thus, reduce the level of emotional burden on the caregivers [3, 7]. A community reintegration programme seems to be beneficial for the most vulnerable patients with acquired brain injury [8-10] and can lead to functional improvements in the domains of independent living, employment, emotional well-being and quality-of-life $[9,10]$. In a recent systematic review considering chronic brain injury patients, only three studies were found dealing with the psychosocial effects of residential community reintegration programmes [11]. Yet, none of these studies investigated the concomitant effects of the treatment on the caregivers.

Therefore, the aim of this study was to investigate the effects of a residential community reintegration programme on the caregivers. Specific questions were whether the residential community reintegration programme directed at the patients:

(1) would be effective in reducing caregivers' emotional burden as well as improving caregivers' psychological health and

(2) would lead to changes in family functioning and family dynamics.

\section{Methods}

\section{Participants}

As part of a larger study on the effects of the Brain Integration Programme [10], the primary caregivers of all patients admitted between June 2004 and February 2007 were eligible for this study. The patients were selected for treatment by means of a semi-structured interview which was performed by a physiatrist and a neuropsychologist using the following inclusion criteria: (1) having sustained acquired brain injury (traumatic, stroke, tumour, encephalitis, hypoxia); (2) having problems in social areas, emotional disturbances and labour/work integration; and (3) being 18 years and older. Exclusion criteria were (1) suitability for other (outpatient) cognitive rehabilitation programmes; (2) severe disruptive behaviour posing danger to other patients or staff; (3) complete lack of problem awareness leading to lack of willingness to change; (4) severe memory problems leading to absent or very limited ability to store new information; and (5) severe drug addiction or, in the case of mild drug addiction, unwillingness to stop drug abuse $[9,10]$.

The primary caregiver, who was at least 18 years old, was asked to fill out the questionnaires. No additional inclusion criteria were used. The study was approved by the regional medical-ethics committee. All patients agreed upon involving the caregivers and gave oral and written informed consent according to the declaration of Helsinki [12]. The caregivers gave oral consent.

\section{Intervention}

The Brain Integration Programme aims at optimal community integration. The essence of the programme is to teach patients to re-establish a balance in their daily activities during domestic life, education/work, leisure time and social interactions, taking into account their possibilities and limitations [13] and to adjust the environment with proper paid attendant care. The programme is provided in a residential setting in one rehabilitation centre in the Netherlands, serving as a tertiary referral centre. The treatment programme is directed at the patients and described in more detail elsewhere $[9,10]$. Caregivers are offered individual education about brain injury and its behavioural consequences. They also receive psychosocial support by means of individual counselling, when necessary. If they wished they could attend discussions after team meetings and they received information by the rehabilitation nurses through regular phone calls.

\section{Design and procedure}

A prospective cohort study was conducted using a 3-month waiting list control period and a 1-year follow-up. Outcome assessments were performed at inclusion (T0), at the start of the treatment 3 months later (T1), at the end of the treatment (T2) and at follow-up 1 year after the end of treatment (T3). At T0 the caregiver questionnaires were selfcompleted by the primary caregiver while they visited the rehabilitation centre. At T1, T2 and T3 the questionnaires were sent by an independent test assistant and returned by the caregivers, all by mail. 


\section{Outcome measures}

Outcome measures were selected to assess emotional burden and psychological health on the one hand (research question 1) and family functioning and family dynamics on the other hand (research question 2).

Caregivers' emotional burden. Few standardized outcome measures considering caregivers' burden have been developed $[6,14]$. Information about responsiveness of existing burden-of-care scales is still lacking or inconclusive $[14,15]$ and, up to now, no gold standard has been developed. For this reason, this study used a relatively new instrument, the Involvement Evaluation Questionnaire for Brain Injury (IEQ-BI), which has been adapted for and validated in the brain injury population [14]. This scale is an originally Dutch self-report questionnaire with 31 items that has been developed to assess caregivers' worries, coping and emotional burden as a consequence of illness of their relative $[16,17]$. The IEQ-BI has a sum score based on 27 items and comprises four sub-scales:

(1) Tension, which refers to a possibly strained interpersonal atmosphere.

(2) Supervision, given by caregivers of patients' medicine intake, sleep, dangerous behaviours, etc.

(3) Worrying, which covers painful interpersonal cognitions, for instance about patient's safety, health and healthcare.

(4) Urging, which refers to activities such as stimulating the patient to take care of himself, eat appropriately and undertake sufficient activities.

The IEQ-BI showed good validity, internal consistency and responsiveness [14]. A lower score represents a lower level of experienced burden.

Psychological health. The 12-item version of the General Health Questionnaire [18, 19] (GHQ) is a widely used self-report screening instrument for psychological health in general healthcare. The GHQ is used as a case detector for mental health problems. It showed a high sensitivity and high specificity with an area under the receiver operating characteristic of 0.88 in 5438 general healthcare patients [19]. A lower score represents healthier functioning.

Family functioning and family dynamics. The Dutch version of the Family Assessment Device [20] (FAD) is a widely used self-report questionnaire. The FAD [21] comprises 60 items and is based on the McMaster model of family functioning and family dynamics [20, 22]. According to many researchers, family functioning and family dynamics are rather stable characteristics which are related to both physical and psychiatric disorders [20, 22, 23]. The FAD contains seven sub-scales: (1) Problem-solving, (2) Communication, (3) Roles, (4) Affective responsiveness, (5) Affective involvement, (6) Culture and (7) General functioning. The concurrent and discriminant validity have been shown to be good [22] and the internal consistency of the sub-scales appeared to be moderate [24]. Furthermore, the 1 week test-re-test reliability was moderate as well [23]. Cut-off scores were determined per sub-scale to differentiate healthy from unhealthy families [23] and the diagnostic confidence, being the proportion of correctly identified cases compared with expert opinion, was between 0.68-0.89 [23]. The FAD General functioning subscale is applied in cross-sectional brain injury research $[22,24,25]$. The concurrent and divergent validity of the sub-scales of the Dutch FAD was moderate-to-good [22]. In this version of the FAD, a higher score represents healthier functioning.

\section{Statistical analyses}

The characteristics of the caregivers and the patients are presented using descriptive statistics. A withinsubject MANOVA with Time as a factor was first done on all 13 outcome measures together (five IEQ-BI scales; seven FAD scales and GHQ) to assess whether there was an overall significant time effect. To determine the effects on specific outcome measures, a significant overall time effect was further analysed with ANOVA using Sidak adjustments for post-hoc comparisons. To determine the effect size, the partial Eta squared was calculated for each outcome measure. The partial Eta squared was considered small when ranging from 0.05-0.1, moderate from $0.1-0.2$ and large when greater than 0.2 [26]. Next, a pair-wise ANOVA was performed for each outcome measure with a significant time effect to determine when the changes occurred. Alpha was set at 0.05 for statistical significance and $p$-values were Huynh-Feldt corrected where appropriate. All analyses were performed with SPSS17.

\section{Results}

Forty-one caregivers of patients with acquired brain injury were included simultaneously with the patients that were included in the Brain Integration Programme effect study. No caregiver refused. At follow-up, data were available for $38(92.7 \%)$ of the 41 patients. The caregivers were predominantly female $(n=28)$, their mean age was $48(\mathrm{SD}=8.3)$ 
Table I. Caregivers' and patients' characteristics $(n=41)$.

\begin{tabular}{lrlrr}
\hline & Mean & SD (range) & $n$ & $\%$ \\
\hline $\begin{array}{l}\text { Caregivers } \\
\text { Age in years }\end{array}$ & 47.9 & $8.3(25-61)$ & & \\
Relation & & & 33 & 80.5 \\
Parent & & & 6 & 14.6 \\
Spouse & & & 2 & 4.8 \\
Sibling & & & & \\
Patients & 23.7 & $6.5(18-49)$ & & \\
Age in years & 4.6 & $5.4(0.5-26.3)$ & & \\
Time since onset in years & & & & \\
Lowest initial GCS score, & 7.1 & $4.7(3-15)$ & & \\
$\quad \begin{array}{l}\text { TBI patients within } \\
\quad 24 \text { hours }\end{array}$ & & & & \\
Coma duration in days & 26.8 & $85.3(0-135)$ & & \\
\hline
\end{tabular}

$\mathrm{SD}=$ Standard Deviation, $\mathrm{GCS}=$ Glasgow Coma Scale, $\mathrm{TBI}=$ Traumatic Brain Injury.

Table II. ANOVA of within-subjects time effects $(n=38)$.

\begin{tabular}{lccc}
\hline Outcome & \multicolumn{3}{c}{$\begin{array}{c}\text { Degrees of } \\
\text { Freedom }\end{array}$} \\
\hline IEQ-Balue \\
Tension & 7.6 & $2.1,77.3$ & $0.001^{\star}$ \\
Supervision & 5.1 & $2.1,78.2$ & $0.007^{\star}$ \\
Worrying & 2.1 & $1.9,70.2$ & 0.131 \\
Urging & 3.5 & $2.5,91.4$ & $0.026^{\star}$ \\
FAD General functioning & 7.8 & $2.6,97.8$ & $0.000^{\star}$ \\
Problem-solving & 0.0 & $2.5,93.9$ & 0.977 \\
Communication & 0.8 & $2.6,95.4$ & 0.476 \\
Roles & 0.7 & $2.6,97.3$ & 0.552 \\
Affective responsive & 0.5 & $2.7,98.9$ & 0.660 \\
Affective involvement & 1.4 & $2.6,94.4$ & 0.244 \\
FAD Culture & 0.5 & $2.3,86.2$ & 0.652 \\
GHQ & 0.2 & $2.6,94.8$ & 0.890 \\
\hline
\end{tabular}

${ }^{\star} p<0.05$ Huynh-Feldt corrected $p$-values where appropriate. IEQ-BI = Involvement Evaluation Questionnaire for Brain Injury, $\mathrm{FAD}=$ Family Assessment Device, $\mathrm{GHQ}=$ General Health Questionnaire.

years and most caregivers $(n=33)$ were parents (Table I). Of the corresponding patients, 30 patients had sustained traumatic brain injury (TBI), six brain tumour, two encephalitis, two hypoxia and one patient a stroke. Patients had a chronic brain injury $($ mean $=4.6$ years post-onset, $\mathrm{SD}=5.4)$. Patients were predominantly male $(n=27)$ and their mean age was $23.7(\mathrm{SD}=6.5)$ years (Table II). Of the patients with TBI, $80 \%$ had sustained a severe injury (Glasgow Coma Scale 3-8) and 20\% a mild injury (Glasgow Coma Scale 13-15); however, always with trauma-related abnormalities on CT or MRI of the brain.

The mean duration of the Brain Integration Programme was 196.2 days $(\mathrm{SD}=61.9$, range $=$ 44-357, median $=199$ days). The hours of participation of the caregivers in the treatment was estimated to be 7.5 hours in total per person.
Table III. Partial $\eta^{2}$ values of within-subjects time effects $(n=38)$.

\begin{tabular}{lc}
\hline Outcome & Partial $\eta^{2}$ \\
\hline IEQ-BI Sum score & 0.17 \\
Tension & 0.12 \\
Supervision & 0.05 \\
Worrying & 0.09 \\
Urging & 0.17 \\
FAD General functioning & 0.00 \\
Problem-solving & 0.02 \\
Communication & 0.02 \\
Roles & 0.01 \\
Affective responsive & 0.04 \\
Affective involvement & 0.01 \\
Culture & 0.01 \\
GHQ & 0.11 \\
\hline IEQ-BI = Involvement Evaluation Questionnaire \\
for Brain Injury, FAD = Family Assessment \\
Device, GHQ = General Health Questionnaire.
\end{tabular}

MANOVA showed an overall significant effect of Time on all 13 outcome measures together (five IEQ-BI sub-scales, seven FAD sub-scales and GHQ; $\left.T^{2}=9.1, F_{15,317}=64.1, p=0.000\right)$. In addition, ANOVA showed significant time effects for four of the five IEQ-BI sub-scales (Tension, Worrying, Urging and Sum score) as well as for the GHQ (Table II). On the FAD sub-scales, ANOVA showed no significant time effects. The effect sizes for the IEQ-BI sub-scales Tension, Urging and Sum Score were moderate (partial $\eta^{2}=0.12,0.17$ and 0.17 , respectively) as was the effect size for the GHQ (partial $\eta^{2}=0.11$ ). The effect sizes for the IEQ-BI sub-scales Supervision and Worrying were small (partial $\eta^{2}=0.05$ and 0.09 , respectively, see Table III).

Pair-wise ANOVA (Table IV) showed significant changes at follow-up compared to at inclusion on the IEQ-BI Sum score, Tension, Worrying and Urging and on the GHQ as well. Furthermore, there were significant changes on the IEQ-BI Tension and IEQBI Sum score during the waiting list period. No significant change was found immediately after treatment for any outcome measure. None of the outcome measures showed significant deterioration at follow-up. Visual analysis of all IEQ-BI sub-scales and the GHQ showed a consistent reduction of the scores (see Figures 1-3), indicating a positive effect at follow-up.

\section{Discussion}

This prospective cohort study, using a 3-month waiting list control period, is the first to examine the effects on caregivers of a residential community reintegration programme (Brain Integration Programme) directed at patients with chronic 
Table IV. Pair-wise post-hoc comparisons for T0-T1, T1-T2, T2-T3 and T0-T3.

\begin{tabular}{lllrrrrrr}
\hline Outcome & T0-T1 & $p$-value & T1-T2 & $p$-value & T2-T3 & $p$-value & T0-T3 & $p$-value \\
\hline IEQ-BI Sum score & 6.66 & $0.010^{\star}$ & 0.47 & 1.000 & 2.42 & 0.296 & 9.55 & $0.004^{\star}$ \\
Tension & 2.18 & $0.016^{\star}$ & 0.00 & 1.000 & 0.53 & 0.879 & 2.71 \\
Supervision & 0.132 & 0.99 & 0.18 & 0.998 & 0.66 & 0.280 & 0.97 & 0.365 \\
Worrying & 1.42 & 0.125 & -0.13 & 1.000 & 0.90 & 0.360 & 2.18 & $0.028^{\star}$ \\
Urging & 2.18 & 0.063 & 0.50 & 0.981 & 0.84 & 0.520 & 3.53 & $0.001^{\star}$ \\
GHQ & 1.03 & 0.201 & -0.11 & 1.000 & 0.95 & 0.311 & 1.87 & $0.016^{\star}$
\end{tabular}

${ }^{\star} p<0.05$ with Sidak adjustment.

$\mathrm{T} 0=$ at inclusion, $\mathrm{T} 1=$ at start treatment, $\mathrm{T} 2=$ post-treatment, $\mathrm{T} 3=$ at 1 -year follow-up, IEQ-BI $=$ Involvement Evaluation Questionnaire for Brain Injury, FAD = Family Assessment Device, $\mathrm{GHQ}=$ General Health Questionnaire

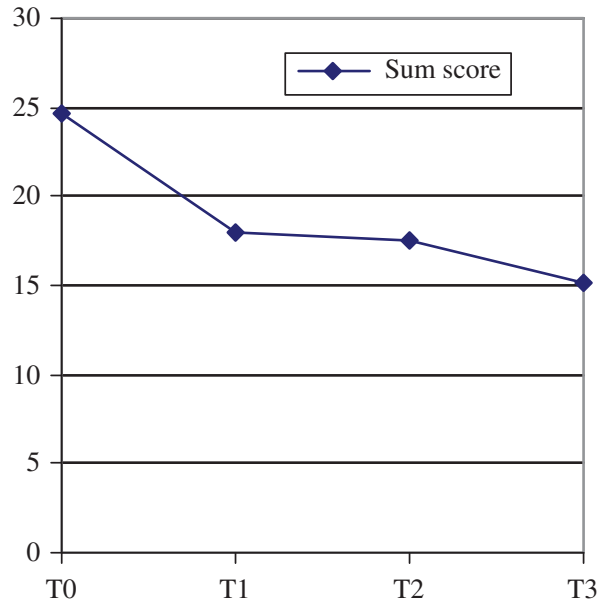

Figure 1. IEQ-BI sum score. T0 $=$ at inclusion, $\mathrm{T} 1=$ at start of treatment, $\mathrm{T} 2=$ post-treatment, $\mathrm{T} 3=$ at 1 -year follow-up.

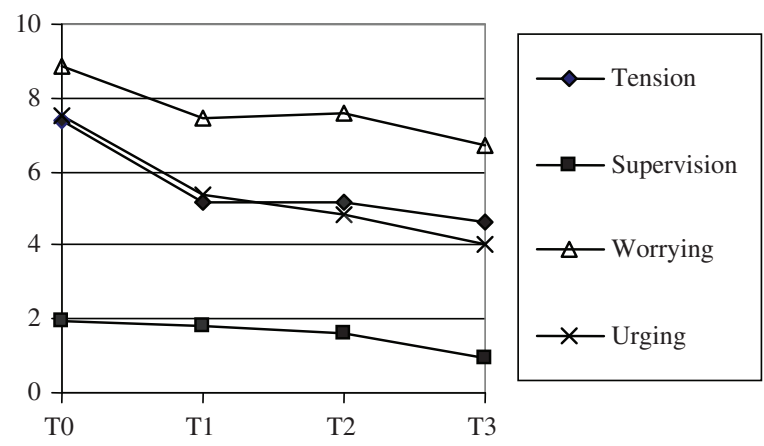

Figure 2. IEQ-BI sub-scales. $\mathrm{T} 0=$ at inclusion, $\mathrm{T} 1=$ at start of treatment, $\mathrm{T} 2=$ post-treatment, $\mathrm{T} 3=$ at 1 -year follow-up.

acquired brain injury with psychosocial problems hampering societal participation. In a companion paper of this study that reported the effects of the programme on the patients, functional improvements were found in the domains of independent living, societal participation, emotional well-being and quality-of-life [10].

\section{Emotional burden and psychological health}

With regard to emotional burden as well as psychological health of the caregivers, the results showed

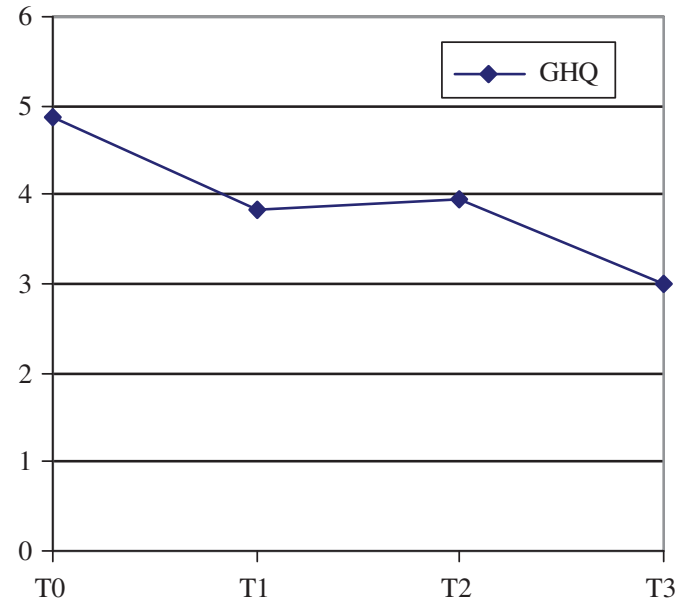

Figure 3. GHQ score. T0 = at inclusion, $\mathrm{T} 1=$ at start of treatment, $\mathrm{T} 2=$ post-treatment, $\mathrm{T} 3=$ at 1 -year follow-up.

significant changes at 1-year follow-up (T3) compared to the moment of inclusion into the programme (T0). There was a significant decrease in the IEQ sub-scales Tension and Sum score at the start of treatment compared to the moment of inclusion 3 months earlier. However, there were no significant changes between the start and the end of treatment. On the GHQ and all IEQ scales slight further improvements were present at follow-up in the expected direction, indicating some additional decrease in emotional burden and better psychological health. It seems that emotional burden and psychological health are determined primarily by the worries and concerns of the caregivers about the patients. Therefore, questionnaires assessing emotional burden and psychological health may be 'anticipatory' measures that are sensitive to expected changes rather than actual changes in patients' functioning and participation [14].

Patients had a chronic brain injury (mean $=4.6$, $\mathrm{SD}=5.4$ years) and were functioning in a stable (although often sub-optimal) situation before inclusion in the Brain Integration Programme. In this perspective, spontaneous changes in the emotional burden or psychological health of the caregivers were 
not expected. Therefore, the beneficial effects observed after inclusion but before the start of the treatment probably reflect the hopes and expectations of the caregivers rather than actual changes. Of course, these expected changes needed to be translated into actual changes to find stable scores at the end of the treatment. The slight further improvements observed at follow-up further confirm that the expected improvements were indeed realized.

\section{Family functioning and family dynamics}

With regard to family functioning and family dynamics the results showed no significant changes. Family functioning and family dynamics are considered to be rather 'stable' constructs [20,22] that can be influenced by physical and psychiatric disorders $[20,22,23]$. This 'stability' might be the reason for the absence of any change. In a recent study on the effect of the Brain Injury Family Intervention, Kreutzer et al. [4] used several outcome measures including the FAD General functioning sub-scale. They too found treatment effects on several other outcome measures, but not on the FAD. Apparently, the FAD lacks sensitivity as an outcome measure in rehabilitation studies. The FAD was initially selected as an outcome measure based on promising crosssectional studies [22, 24, 25]. However, based on the present study and the study by Kreutzer et al. [4], the suitability of the FAD for longitudinal effect studies seems to be questionable.

\section{Study limitations}

The observed effects on the caregivers were relatively small compared to the beneficial effects on the patients [10], which can be explained by the fact that the Brain Integration Programme was primarily directed at the patients. The involvement of the caregivers mainly concerned the improvement of the functioning and behaviour of the patients. This was done by providing them information that focused on the reintegration and psychosocial problems of the patients, with little emphasis on the problems of the caregivers themselves and hardly any counselling. Furthermore, the overall time of caregivers' involvement was limited to 7.5 hours. Visser-Meily et al. [2] reported that at least 8 hours of counselling seem to be necessary to obtain any positive effects on caregivers and that counselling should be directed at the problems of the caregivers themselves, not merely on the problems of the patients. Boschen et al. [5] advised to use active education, skills training and a support-group approach for caregivers of patients with acquired brain injury, because support groups help to address the educational and psychological needs of caregivers. Finally, teaching methods need to become available that aim to adjust the caregivers to the psychosocial consequences of brain injury, to enhance their communication skills and to help them address their concerns over the future [5]. These treatment elements directed at the caregivers themselves were only partly fulfilled in this study. Recently interventions have been developed with promising initial results $[3,27,28]$. The incorporation of these interventions into residential community reintegration programmes could potentially lead to additional beneficial effects on the caregivers. Due to different causes of distress in parents and spouses of patients with brain injury [29] specifically adapted interventions might be necessary. In future studies clearly defined family interventions need to be systematically performed and studied.

\section{Conclusion}

A residential community reintegration programme directed at patients with chronic acquired brain injury and subsequent psychosocial problems hampering societal participation may have concomitant beneficial effects on the emotional burden and psychological health of caregivers. The beneficial effects on caregivers show an earlier time course when compared to the effects on patients, indicating an 'anticipation' phenomenon. Future studies should also aim at interventions directed specifically on the problems of the caregivers themselves.

\section{Acknowledgement}

We would like to thank Dr B. van Wijngaarden for providing us the original Involvement Evaluation Questionnaire and for helping us with creating the Involvement Evaluation Questionnaire for Brain Injury.

Declaration of Interest: This work was supported by Johanna Child Fund and BIO Child Rehabilitation Fund [grant number 2003/0120009]. The authors report no conflicts of interest. The authors alone are responsible for the content and writing of the paper.

\section{References}

1. Riley GA. Stress and depression in family cares following traumatic brain injury: The influence of beliefs about difficult behaviours. Clinical Rehabilitation 2007;21:82-88.

2. Visser-Meily JMA, Heugten CM van, Post MWM, Schepers VM, Lindeman E. Intervention studies for caregivers of stroke survivors, a critical review. Patient Education and Counseling 2005;56:257-267.

3. Kreutzer JS, Rapport LJ, Marwitz JH, Harrison-Felix C, Hart T, Glenn M, Hammond F. Caregivers' well-being after 
traumatic brain injury: A multicenter prospective investigation. Archives of Physical Medicine and Rehabilitation 2009;90:939-946.

4. Kreutzer JS, Stejskal TM, Ketchum JM, Marwitz JH, Taylor LA, Menzel JC. A preliminary investigation of brain injury family intervention: Impact on the family members. Brain Injury 2009;23:535-547.

5. Boschen KA, Gargaro J, Gan G, Gerber G, Brandys C. Family interventions after acquired brain injury and other conditions: A critical appraisal of the quality of evidence. Neurorehabilitation 2007;22:19-41.

6. Struchen MA, Atchison TB, Roebuck TM, Caroselli JS, Sander AM. A multidimensional measure of caregiving appraisal: Validation of the caregiver appraisal scale in traumatic brain injury. The Journal of Head Trauma Rehabilitation 2002;17:132-154.

7. Gan C, Gargaro J, Brandys C, Gerber G, Boschen KA. Family caregivers' support needs after brain injury: A synthesis of perspectives from caregivers, programs, and researchers. Neurorehabilitation 2010;27:5-18.

8. Malec JF, Basford JS. Postacute brain injury rehabilitation. Archives of Physical Medicine and Rehabilitation 1996;77: 198-207.

9. Geurtsen GJ, Martina JD, Heugten CM van, Geurts ACH. A prospective study to evaluate a new residential community integration programme for severe chronic brain injury: The Brain Integration Programme. Brain Injury 2008;22: 545-554.

10. Geurtsen GJ, Heugten CM van, Martina JD, Rietveld ACM, Meijer R, Geurts ACH. A prospective study to evaluate a residential community reintegration programme for patients with chronic acquired brain injury. Archives of Physical Medicine and Rehabilitation 2011;92:696-704.

11. Geurtsen GJ, Heugten CM van, Martina JD, Geurts ACH. Comprehensive rehabilitation programmes in the chronic phase after severe brain injury: A systematic review. Journal of Rehabilitation Medicine 2010;42:97-110.

12. Carlson RV, Boyd KM, Webb DJ. The revision of the Declaration of Helsinki: Past, present and future. British Journal Clinical Pharmacology 2004;57:695-713.

13. Mateer CA, Sira CS, O'Connell ME. Putting Humpty Dumpty together again: The importance of integrating cognitive and emotional Interventions. The Journal of Head Trauma Rehabilitation 2005;20:62-75.

14. Geurtsen GJ, Meijer R, Heugten CM van, Martina JD, Geurts ACH. Experienced emotional burden in caregivers: Psychometric properties of the Involvement Evaluation Questionnaire in caregivers of brain injured patients. Clinical Rehabilitation 2010;24:935-943.

15. Visser-Meily JMA, Post MWM, Riphagen II, Lindeman E. Measures used to assess burden among caregivers of stroke patients: A review. Clinical Rehabilitation 2004;18:601-623.

16. Wijngaarden B van, Schene AH, Koeter M, Vazquez-Barquera JL, Knudsen HC, Lasalvia A, McCrane P. The Epsilon Study Group. Caregiving in schizophrenia: Development, internal consistency and reliability of the Involvement Evaluation Questionnaire European Version. The British Journal of Psychiatry 2000;177(Suppl 39):s21-s27.

17. Wijngaarden B van, Schene A, Koeter M. Caregiver consequences in The Netherlands and other European countries: The development and use of the Involvement Evaluation Questionnaire. In: Lefley HP, Johnson DL, editors. Family interventions in mental illness. International perspectives. Westport, CT: Praeger Publishers; 2002. pp 145-169.

18. Goldberg D, Williams P. A user's guide to the General Health Questionnaire. Windsor: NFER-Nelson; 1988.

19. Goldberg DP, Gater R, Sartorius N, Ustun TB, Piccinelli M, Gureje O, Rutter C. The validity of two versions of the GHQ in the WHO study of mental illness in general health care. Psychological Medicine 1997;27:191-197.

20. Wenniger WF, Hageman WJ, Arrindell WA. Cross-national validation of dimensions of family functioning: First experiences with the Dutch version of the McMaster Family Assessment Device. Personality and Individual Differences 1993;14:769-781.

21. Epstein NB, Baldwin LM, Bishop DS. The McMaster Family Assessment Device. Journal of Marital \& Family Therapy 1983;9:171-180.

22. Winstanley J, Simpson G, Tate R, Myles B. Early indicators and contributors to psychological distress in relatives during rehabilitation following severe traumatic brain injury: Findings from the brain injury outcomes study. The Journal of Head Trauma Rehabilitation 2006;21:453-466.

23. Miller IW, Epstein NB, Bishop DS, Keitner GI. The McMaster Family Assessment Device: Reliability and validity. Journal of Marital \& Family Therapy 1985;11:345-356.

24. Ergh TC, Papport LJ, Coleman RD, Hanks RA. Predictors of caregiver and family functioning following traumatic brain injury: Social support moderates caregiver distress. The Journal of Head Trauma Rehabilitation 2002;17:155-174.

25. Nabors N, Seacat J, Rosenthal M. Predictors of caregiver burden following traumatic brain injury. Brain Injury 2002;16:197-203.

26. Cohen J. Statistical Power Analysis for the Behavioral Sciences. New York: Academic Press; 1966.

27. Gan C, Gargaro J, Kreutzer JS, Boschen KA, Wright V. Development and preliminary evaluation of a structured family system intervention for adolescents with brain injury and their families. Brain Injury 2010;24:651-663.

28. Kreutzer JS, Stejskal TM, Ketchum JM, Marwitz JH, Taylor LA, Menzel JC. A preliminary investigation of the brain injury family intervention: Impact on family members. Brain Injury 2009;23:535-547.

29. Anderson MI, Simpson GK, Morey PJ, Mok MMC, Gosling TJ, Gillett LE. Differential pathways of psychological distress in spouses vs. parents of people with severe traumatic brain injury (TBI): Multi-group analyses. Brain Injury 2009;23:931-943. 